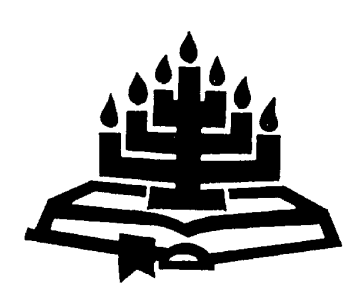

\title{
Liggaamstaal as kommunikasie: perspektiewe uit die Hebreeuse Bybel
}

\author{
Paul A. Kruger \\ Departement Antieke Studie \\ Universiteit van Stellenbosch \\ STELLENBOSCH \\ E-pos: pak@akad.sun.ac.za
}

\begin{abstract}
Body language as communication: perspectives from the Hebrew Bible

This contribution treats aspects of the important source of nonverbal communication in the Hebrew Bible. It focuses especially on the following themes:

- the problem of terminology,

- legal acts, with special emphasis on the idea of dissociation,

- the manner in which some emotions (shame, disgust) are displayed nonverbally,

- the manifestation of nonverbal communication in narrative literature (especially in the nonverbal category "proxemics" in Ruth 2-3).
\end{abstract}

\section{Inleiding}

In 'n wêreld wat beheer word deur mondelinge en menigvuldige vorme van geskrewe kommunikasie is ' $n$ mens geneig om te vergeet dat daar ook ander wyses is waarop boodskappe effektief oorgebring kan word. Die verwaarlosing van hierdie unieke wyse van informasie-oordrag is volgens die antropoloog Farnell kultureel bepaal en kan teruggevoer word na "... a long-standing bias against the body in the Western philosophical and religious traditions ..." (Farnell, 1996:536). In hierdie model is die menslike verstand vir lank gereken as die setel van rasionaliteit, terwyl die liggaam beskou is as die "material locus for physical expression of irrationality, feeling and emotion" (Farnell, 1996:537). Liggaamstaal is daarom as "primitief" gesien en as 'n aanduiding van ongekultiveerdheid. As 'n mens bydraes lees oor die tema van liggaamstaal in die 
Hebreeuse Bybel, veral in die eerste deel van die eeu, dan is dié negatiewe sentiment ten opsigte van die wyse van informasie-oordrag nog duidelik aanwesig. So skryf Mackie byvoorbeeld in 1899: "Gesture is much resorted to by Orientals in the communication of their thoughts and expression of their feelings. Where we control our feelings, they are controlled by them" (Mackie, 1899:162; my beklemtoning).

Ook vandag nog maak ons geen geheim van ons voorkeur vir die verbale as die primêre wyse van kommunikasie nie. Selfs die tipering "nie-verbale" kommunikasie gee uitdrukking aan ons "logocentric bias", soos die antropoloog Polhemus dit noem (1975:14). Dit is daarom heel ironies, sê Polhemus (1975: $14)$, "... that the academic world - that fantastic machine geared for the production of verbal jargon - should focus its 'logocentric' attention upon the movements, gestures, postures and expressions of the physical body. Surely the subject of the human body is more suited for the dance-floor than for the lecturer's podium". So 'n herfokussering is egter soms nodig, veral as daar in gedagte gehou word wat, Hall, die skepper van die begrip "proxemics" ("spacial behaviour") beweer. In sy welbekende boek Silent language (Hall, 1959) bespreek hy tien verskillende wyses van menslike aktiwiteit wat hy tuisbring onder die noemer "primary message systems". Net een van hulle het met die verbale te make.

'n Studie van die aard en omvang van nie-verbale kommunikasie is op sigself 'n baie interessante aangeleentheid omdat gebare as kommunikasiemedium ouer as taal is. Talle woorde of woordkombinasies kan teruggevoer word na eertydse gebaretaal. So hang ons woord vir "hulde" saam met 'n wortel (hal) wat beteken "om jouself neer te buig". "Seën" hou verband met "om 'n (kruis)teken te maak" (Schmidt-Wiegand, 1971:1412). Ander kombinasies of idiome in ons daaglikse woordeskat, wat ook nog getuig van die oorspronge in gebaretaal, is byvoorbeeld, "ek het hand en mond belowe", "ek hou my hand op my hart", "iemand deur die vingers sien", "iemand op die vingers tik" (kyk die voorbeelde wat Schmidt-Wiegand, 1982:364 en Kienast, 1996:115 noem).

Wat die Ou Nabye Ooste betref, was gebaretaal van besondere belang om verskeie redes waarvan ek net twee noem. Eerstens, liggaamstaal in daardie deel van die wêreld was die normale en nie die buitengewone wyse van inligtingoordrag nie. Watter integrale deel dit van 'n Oosterling se daaglikse bestaan gevorm het, kom nog duidelik na vore in beskrywings van reise in die Ou Ooste in die negentiende eeu. So berig die Duitser Petermann, byvoorbeeld:

By 'n groet, of by die uitdrukking van dankbetuiging, strek die regterhand na die grond om daarvandaan ' $n$ bietjie stowwerigheid te neem. Dan beweeg dit na die bors, die mond en die voorkop. Die mindere gryp die regterhand van die meerdere, soen dit en plaas dit as 'n teken van 
onderdanigheid op die kop ... as teken van bevestiging, word die kop heen en weer geskud ... wil hulle te kenne gee dat hulle niks met 'n saak te doen het nie, word die deel van die kledingstuk naaste aan die bors geskud.

[Bei der Begrüssung wie beim Ausdruck des Dankes fahren sie mit der rechten Hand nach unten, gleichsam um Staub von dem Boden zu nehmen, dann nach der Brust, dem Mund und der Stirn, und die Untergebenen ergreifen die Rechte des Höheren, küssen sie und legen sie dann zum Zeichen der Unterwürfigkeit auf ihren Kopf ... wenn sie etwas bejahen wollen, so schütteln sie mit dem Kopfe ... wollen sie bemerklich machen, dass sie keinen Anteil an einer Sache haben, so greifen sie mit der rechten Hand an den oberen Rockzipfel und schütteln ihn] - aangehaal deur Goldziher, 1886:370.

Let daarop dat al hierdie handelinge getuig van 'n totale afwesigheid van taal.

Tweedens, in baie van hierdie tipe pre-industriële gemeenskappe (deur sommige ook "performative cultures" genoem; kyk Hibbits, 1992) het mense in die juridiese sfeer veel eerder van handelinge as van die geskrewe medium van kommunikasie gebruik gemaak. Die resultaat of uitkoms van 'n wetlike aangeleentheid is nie "geskryf"/"beskryf" nie; dit is "gedoen". Of soos Maine gepas opmerk: "Gestures and words took the place of written phraseology" (1861:268). Tot in die tyd van die Middeleeue verklaar die gebrek aan geletterdheid die populariteit en belang van gebaretaal. Dit was eers in die dertiende eeu met die opkoms van staatsburokrasieë wat geletterdheid aangehelp het, dat daar veranderings in dié opsig gekom het (Schmitt, 1991:59).

In die studie van hierdie "nie-gesproke" wyse van kommunikasie van die antieke, moet ondersoekers natuurlik besef dat hulle nooit, soos hedendaagse antropoloë, "deelnemende waarnemers" ("participant observers") kan word nie. Al wat hulle ter beskikking het, is woorde op papier. "This means that we have to take into account all of the biases, the weight of vocabulary, and the ideologies that intrude between the gestures, the texts, and ourselves" (Schmitt, 1991:63). Dit maak die taak van interpretasie en vertaling van dié tipe informasie so 'n uiters moeilike saak.

As tekskorpus vir hierdie bydrae word gekonsentreer op die Hebreeuse Bybel as belangrike tekskorpus van die $\mathrm{Ou}$ Nabye Ooste. Opmerkings gaan oor die volgende sentrale aspekte van nie-verbale kommunikasie met betrekking tot dié teksversameling gemaak word:

- Die probleem met betrekking tot terminologie

- Performatiewe handelinge en die juridiese aard daarvan

- Die uitdrukking van emosie op nie-verbale wyse 
- Nie-verbale kommunikasie en narratiewe literatuur

\section{Die probleem met betrekking tot terminologie}

As 'n mens die literatuur nagaan wat die afgelope eeu oor die onderwerp met betrekking tot die Mediterreens-Ou Oosterse wêreld verskyn het, dan spring drie wyses van tipering onmiddellik in die oog: "gebare", "nie-verbale kommunikasie" en "simboliese handelinge". Een van die vroegste publikasies in die verband is, is die nog steeds baie leesbare werk van Carl Sittl (1890) met die titel Die Gebärden der Griechen und Römer. Blaai 'n mens deur die boek, dan kom jy agter dat die noemer "gebare" 'n baie breë veld bestryk. Hieronder bring hy tuis alle "nie-meganiese bewegings van die menslike liggaam" ("nicht mechanischen Bewegung des menschlichen Körpers"; 1890:1), wat aspekte insluit soos die uitdrukking van emosie ("Ausdruck von Gefühlen und Gemütsbewegung") en selfs juridiese simboliek ("Rechtssymbolik"). Laasgenoemde aspekte word tans gekategoriseer onder die sambreelterme "nie-verbale kommunikasie" en "simboliese handelinge", respektiewelik. As hierdie breë definisie van die term "gebaar" vergelyk word met die baie meer onlangse een van Kendon uit die sosiale wetenskappe ("An action by which a thought, feeling, or intention is given conventional and voluntary expression", 1981:28), dan blyk dit dat Sittl se tipering van die kategorie "gebaar" gans te omvangryk is. Die uitdrukking van emosies kan nie hieronder ressorteer nie omdat emosie in die meeste gevalle iets onwillekeurigs is. Voorts moet ' $n$ aspek soos regsimboliek ook as 'n aparte kategorie gehanteer word.

In die studie van Gruber uit die tagtigerjare (Aspects of non-verbal communication in the Ancient Near East, 1980) kom 'n mens die begrip "nieverbale kommunikasie" teë. Die grootste deel van sy studie handel oor die uitdrukking van emosies op 'n nie-verbale wyse. Die term "nie-verbale kommunikasie" is die skepping van die psigiater Ruesch en die fotograaf Kees (1956). Hulle baseer hulle studie op die kibernetika en matematiese teorie in verband met informasie. 'n Dekade later word hierdie begrip van toepassing gemaak op ".. any movement or position of the face/or the body" (Ekman \& Friesen, 1969:49). Vandag het die term 'n nog wyer toepassingsveld en verwys dit na "... the emissions of signs by all the nontexical, somatic, artifactual and environmental sensible sign systems contained within a culture ..." (Poyatos, 1987:2). Dit sluit dus aspekte in soos spraakintonasie, praatspoed, reuk, ensovoorts, wat onmoontlik is om af te lei uit literêre tekste, mits dit nie spesifiek vermeld word nie. In die lig van hierdie jongste ontwikkelinge in die studieveld van nie-verbale kommunikasie moet die toewysing van die begrip versigtig gehanteer word. Gruber se toepassing is byvoorbeeld te ambisieus. Uit hoofde van die spektrum wat hy dek (naamlik die uitdrukking van emosies) sou 'n meer 
beperkende titel soos die volgende baie meer gepas wees: "On the expression of some forms of affect displays in the Ancient Near East".

'n Ander begrip wat in die vakliteratuur in dié verband verskyn, is "simbool" ("simboliese handeling"). Vergelyk byvoorbeeld die titels van die studies van Malul (Studies in Mesopotamian legal symbolism, 1988) en Viberg (Symbols of law, 1992). Volgens Malul was "symbolic acts ... not instruments of language, but rather constitutive instruments of law, intended to create and bring about a legal change rather than just communicate it" [1988:22; kyk ook Viberg se definisie (1992:9) wat gebaseer is op dié van Malul]. Om 'n voorbeeld te noem: die uittrek van die sandaal (simbool van mag en eienaarskap) in Rut 4:8, in die teenwoordigheid van getuies, sou volgens dié definisie van Malul die simboliese oordrag van eienaarskap kommunikeer. Hier gebeur egter meer as dit. Die uittrek van die sandaal simboliseer nie alleen die oordrag van eiendom nie, die daad as sodanig is die oordrag van eiendom, soos Hillers tereg aandui (1990:360). Met ander woorde, die aksie van die uittrek van die sandaal het 'n baie bepaalde performatiewe karakter. Dit is die vergestalting van 'n juridiese verandering wat ingetree het en wys nie alleen heen na een nie. Uit hoofde hiervan is dit meer verkieslik om, waar van sodanige handelinge sprake is, binne die juridiese sfeer eerder te praat van "performatiewe handelinge", in plaas van die gebruiklike "simboliese gebare".

\section{Performatiewe handelinge en die juridiese aard daarvan}

Soos bo aangedui, het die beperkte omvang van geletterdheid direk verband gehou met die belangrikheid en populariteit van performatiewe handelinge, spesifiek in die juridiese sfeer. Een van die juridiese areas waar sodanige handelinge ' $\mathrm{n}$ sentrale rol gespeel het, was in die aangaan en verbreking van ooreenkomste of relasies. Gewoonlik het 'n verhouding tot stand gekom wanneer iemand deel geword het van die invloedsfeer van 'n ander. In dié opsig was die liggaam, of aksies wat geassosieer is met daardie intieme, persoonlike item van die liggaam, naamlik klere, van fundamentele belang. By die verbreking van so 'n relasie het die teenoorgestelde gewoonlik plaasgevind: die verhouding word by wyse van spreke "gesny", of so iemand word daaruit geforseer, of hy besluit om hom uit vrye wil daarvan te distansieer. Dit alles kon plaasvind by wyse van sekere gepaste handelinge wat uitgevoer is.

In die studie van Viberg (1992), waarna reeds verwys is, het die klem geval op eersgenoemde aspek, naamlik die smee of aangaan van verhoudinge of relasies. Hy bespreek die volgende performatiewe handelinge: die handdruk, die salwing van die kop met olie, die oordrag van 'n kledingstuk, die gesamentlike maaltyd, die deurboring van die oor van 'n slaaf, die uitsprei van die soom van die kleed 
oor die toekomstige vrou en die neem van 'n kind op die skoot as 'n teken van aanneming. Van die teenoorgestelde betekenisinhoud, naamlik die verbreking van 'n verbintenis, bied hy slegs een voorbeeld aan: die uittrek van die sandaal waarna reeds verwys is. Geen rede word aangevoer vir hierdie oënskynlike wanbalans in sy voorbeelde nie, hoewel hy tog in die Inleiding sê dat hy beoog om die belangrikste voorbeelde in die Hebreeuse Bybel in te sluit. Tog sou hy na 'n hele paar meer voorbeelde van die nuanse van dissosiasie kon verwys het. Hier gaan kortliks na vyf sulke gevalle verwys word.

\subsection{Die was van die hande}

Een van die mees effektiewe maniere waarmee die gedagte van dissosiasie geillustreer kon word, is deur die was van die hande. In die Hebreeuse Bybel word by drie geleenthede hiervan melding gemaak (Deut. 21:6, Ps. 26:6, 73:13; kyk Kruger 1990:164 e.v.).

Die perikoop in Deuteronomium 21:1-9 het te make met die versoening van 'n moord wat gepleeg is deur 'n onbekende hand'. Die oudstes wat in die dorp naaste aan die vermoorde woon, word aangesê om 'n vers te neem, dit na 'n bepaalde spruit af te neem en daar dié se nek te breek. Dan moet hulle soos volg te werk gaan: hulle moet hulle hande was bo-oor die vers waarvan die nek gebreek is en verklaar: "Ons hande het hierdie bloed nie vergiet nie, en ons oë het dit nie gesien nie" (v. 6-7). In die verstaan van dié passasie verwys kommentatore gewoonlik na die ander gevalle (Ps. 26:6 en 73:13) waar sprake is van dieselfde handeling. Daar word spesifiek gemeld dat dit uitgevoer word as bewys van "onskuld". Oor die algemeen word die frase vertaal met: "Ek was my hande in onskuld", wat verwarrend kan wees. Meer verkieslik egter is die vertaling : "Ek was my hande om my onskuld te bewys".

Wat kommentatore van die Deuteronomiumteks verswyg, of nie van bewus is nie, is dat die handeling ' $n$ voorgeskiedenis het. Dit word reeds aangetref in Ugarit (Teks RS 15.92) uit die Laat Bronstydperk. Die teks handel oor 'n ooreenkoms met betrekking tot ' $n$ adopsie en dui aan wat moet gebeur as die geadopteerde nie by die bepalings hou nie: "As Ilkuya van plan is om sy vader te verwerp, moet hy sy hande was en hy sal vry uitgaan in die straat". Die "was van die hande" is 'n performatiewe handeling wat iemand vrystel van 'n sekere verpligting of ooreenkoms (Malul, 1988:136 e.v.; sien ook Kilmer, 1974:180). Hoewel daar 'n verskil is wat konteks betref tussen die Deuteronomium- en Ugarittekste, is die betekenisnuanse dieselfde: dit dui op die distansiëring van 'n objek of aangeleentheid wat die kontaminasie veroorsaak.

$1 \quad$ Viberg (1992:4) verwys na dié voorbeeld, maar bespreek dit nie omdat hy dit reken as "legal acts within cultic law". 


\subsection{Die uitskud van die boonste deel van die kleed}

Die Hebreeuse Bybel verwys ook nog na 'n ander handeling wat min of meer dieselfde betekenis het as die voorafgaande (Kruger, 1990:165 e.v.). Dit kom voor in Nehemia 5:13. Die hoofstuk berig hoe Nehemia sy mede-Jode probeer oortuig om hulle eie mense vry te stel van slawerny (v. 7 e.v.). Die skuldiges beloof dan plegtig om dit te doen waarop Nehemia die priesters byeenroep om die betrokkenes te laat sweer dat hulle by hulle onderneming sal bly. Om die gewigtigheid van hulle besluit nog verder te laat indring, dramatiseer Nehemia, soos die profete van ouds, die straf wat diesulkes sou tref wat nie by hul belofte hou nie. Hy skud die deel van sy kleed naaste aan sy bors en verklaar: "Mag God elkeen wat nie sy woord hou nie, so uit sy huis en sy besittings uitskud ..." (v. 13). Die Hebreeuse woord gôzen ("die deel van die kleed naaste aan die bors") wat die Ou en Nuwe Afrikaanse Vertaling onderskeidelik met "boesem" en "sakke" vertaal, kom nog op twee ander plekke in die Hebreeuse Bybel voor. In Psalm 129:7 verwys dit na die plek waar die gerwebinder dit wat hy afgesny het, dra. In Jesaja 49:22 dui die gôzen op die plek waar 'n kind gedra word. As Nehemia dan sê dat hy sy gôzen uitskud, dan verwys hy na daardie deel van sy kleed naaste aan die bors waar persoonlike en waardevolle besittings gedra is. As iemand dus so 'n handeling uitvoer in teenwoordigheid van getuies, wil hy daarmee verklaar dat hy rein is van enigiets wat daaraan mag kleef. Met ander woorde, volledige distansiëring van enige betrokkenheid by 'n sekere saak of aangeleentheid (Malul, 1988:336 e.v.).

Dié handeling herinner aan 'n soortgelyke een wat Paulus by geleentheid uitvoer (Hand. 18). Toe die Jode hom opponeer en belaster, het hy "sy klere uitgeskud" (en nie "die stof van sy klere afgeskud", soos die Nuwe Vertaling dit weergee nie) en gesê: "Julle bloed is op julle kop. Ek is rein" (v. 6). Met hierdie handeling verklaar hy dat hy hom geheel en al distansieer van enige assosiasie met die Jode.

\subsection{Die stroop van die klere}

Die aantrek van klere het by sekere geleenthede op 'n dieper betekenis as bloot die fisiese daad gewys (kyk bv. Prouser, 1996). Dieselfde is waar van die teenoorgestelde handeling. Dit kon byvoorbeeld dui op (1) vernedering of 'n degradering in status of (2) die einde van 'n ooreenkoms of alliansie aankondig. Wat laasgenoemde betref, is daar ' $n$ magdom voorbeelde uit die Hebreeuse Bybel en die Umwelt. Daar word net na enkeles verwys.

Uit die stad Ugarit vind ons die volgende interessante voorbeeld (Teks RS 17.159). Dit handel oor 'n testament en stipuleer wat met 'n seun gaan gebeur as hy in gebreke sou bly om op te tree op 'n wyse wat sy vader se goedkeuring wegdra. In so 'n geval, moes hy "sy kleed op die stoel agterlaat en padgee" 
(Rummel, 1976:7). Die neerlê van die kleed slaan op die afstanddoen van sy aanspraak op die troon.

Die Hebreeuse Bybel lewer, onder andere, ook die volgende voorbeeld in dié verband op. In Deuteronomium 21:10-13 word voorskrifte gegee hoe daar gehandel moes word met ' $n$ vrou wat 'n krygsgevangene was. Om die plegtige afswering van haar land en haar familie te bekragtig, word haar toekomstige man aangesê om toe te sien dat sy die volgende doen: "Jy moet haar in jou huis bring, haar kop skeer en haar naels knip en die klere waarin sy weggevoer is, uittrek" (vv. 12-13). Die uitvoer van dié handelinge dui op 'n totale opsegging van haar bande met die verlede. Nou is sy vry en gereed om 'n nuwe sosiale relasie aan te gaan (Kruger, 1990:166).

\subsection{Simboliese aktiwiteite: om iemand uit te dryf in die straat}

In sy studie oor juridiese simboliek, dui Malul (1988) oortuigend aan dat daar juridies gesproke 'n duidelike verskil is tussen die "binnesfeer" (daardie domein wat te make het met die familiekring, die huisgesin) en die "buitesfeer" (die straat). Die oorgang vanuit die een sfeer na die ander beteken heel dikwels die oorgang van een juridiese sfeer na ' $n$ ander, met al die juridiese implikasies wat dit inhou (Malul, 1988:129). In dié opsig het die ingang na die huis 'n spesiale plek beklee (kyk Van Gennep, 1965:20 e.v., 57 e.v., Kruger, 1990:167 e.v.). Dit was die simboliese grens tussen die familiekring en die buitewêreld en daarom ook die plek waar vreemdelinge simbolies in die familie ingelyf is en waar lede uit die familie uitgedryf is (Malul, 1988:138). Weer illustreer 'n teks uit Ugarit (RS 8.145; kyk Kilmer, 1974:181) hoe hierdie beginsel gewerk het en weer het dit te make met 'n testament - hierdie keer van 'n man met betrekking tot sy vrou. Dit bepaal dat die twee seuns verplig is om hulle moeder te respekteer en om geen aansprake te maak ten opsigte van hulle pa se eiendom nie. Die een wat dit sou waag, moes 'n boete betaal en "sy mantel aan die (deur) grendel (juridiese grens van die "binnesfeer") ophang en as 'n vry man in die straat ("buitesfeer") uitgaan". Die aflegging van sy kleed stel hom vry van enige verantwoordelikheid met betrekking tot sy vroeëre familie-verbintenis. Die oomblik as hy die juridiese grens van die "binnesfeer" (die huisdeur) oorsteek, ressorteer hy onder 'n ander wetlike domein. 'n Mens kan begryp dat so 'n handeling ingrypende implikasies ingehou het en dat daar baie mooi gedink sou word alvorens tot so finale stap oorgegaan sou word.

Ook in die Hebreeuse Bybel was hierdie juridiese beginsel van die "binne-" en "buitekant" baie prominent. Ter illustrasie kan verwys word na 'n passasie in die boek Josua (Hoofstuk 2). In dié hoofstuk ontvang Ragab die belofte van die twee spioene dat sy en haar familie gespaar gaan bly as sy 'n rooi lyn aan haar venster bind en haar hele familie in haar huis versamel (v. 18). Die spioene vervolg met hulle waarskuwing: "Elkeen wat uit die deure van jou huis buitentoe gaan na die 
straat, se bloed sal op sy hoof wees en ons onskuldig. Elkeen wat by jou in die huis sal wees, dié se bloed sal op ons kop wees" (v. 19).

Ook in die huweliksfeer was die idee van die "binne-" en die "buitekant" baie prominent. Die huweliksband is eers formeel bekragtig wanneer die man sy aanstaande vrou in sy woonplek gebring het (bv. Isak vir Rebekka in Gen. 24:67). Insgelyks is ' $n$ egskeiding ook eers finaal voltrek as die vrou fisies uit die man se persoonlike sfeer (die huis) verdryf is. In Deuteronomium 24:3 staan daar dat in geval van 'n egskeiding die man sy vrou "uit sy huis moet wegstuur". As hy dit nie doen nie, dan val sy juridies nog onder sy sorg. Hierdie gedagte van fisiese verwydering slaan ook nog deur in terme wat vir egskeiding, of vir 'n geskeide vrou gebruik word. 'n Skeibrief bedui letterlik “'n snybrief". Dit "sny" die ongelukkige verbintenis (Jes. 50:1, Jer. 3:8). Verder is die gebruiklike woord vir egskeiding, die woord grsh, wat letterlik beteken "om weg te stuur", "te verban", "uit te dryf'.'n Geskeide vrou is 'n grwsh (Lev. 21:7, Num. 30:10, Eseg. 44:22), letterlik "die een wat weggedryf is". Al hierdie terme dui daarop dat die huweliksband tot 'n einde gekom het en dat die vrou voortaan tot 'n ander wetlike sfeer behoort (Kruger, 1990:168).

\subsection{Om die kleed in iemand se hand agter te laat}

Uit bostaande voorbeelde het dit duidelik geword dat 'n kledingstuk, omdat dit 'n verlengstuk van die persoon self is (sien Petschow, 1971:318), 'n belangrike funksie vervul het in die juridiese sfeer. Genesis 39 bevat ' $n$ ander interessante ritueel in verband met die kleed, maar die diepere juridiese betekenis daarvan word meestal deur kommentatore misgekyk. Dat die handeling wat hier uitgevoer word, 'n definitiewe juridiese konnotasie het, word bevestig deur 'n soortgelyke handeling in vergelykbare omstandighede in die Wysheidsboek van Agikar (kyk onder).

Genesis 39 verhaal die ontmoeting tussen Josef en die vrou van Potifar en hoe hy daarin geslaag het om haar toenaderings te ontwyk. Aanvanklik was haar blatante flankeerdery net van 'n nie-verbale aard. In v. 7 staan daar byvoorbeeld dat sy vir hom "ogies gemaak het"; letterlik: "haar oë na hom opgeslaan het". Dit was egter nie lank nie of sy begin hom bombardeer met haar verbale toenaderings: “... kom lê hier by my" (v. 7, 10). As dit egter blyk dat sy in geeneen van die pogings suksesvol is nie, gaan sy oor tot 'n berekende daad. Terwyl Josef op 'n dag in die huis van sy heer besig is met sy daaglikse roetine “... gryp sy hom aan sy kleed en sê: 'lê by my'. Hy het egter sy kleed in haar hand agtergelaat en buitentoe gevlug" (v. 12). Dit is belangrik om daarop te let wat Josef doen nadat hy die handeling uitgevoer het: hy vlug buitentoe (letterlik: na die straat) en verwyder hom so juridies buite die grense van Potifar se huis (sien bo). 
Twee duidelik onderskeibare handelinge word uitgevoer deur die twee akteurs. Die eerste een deur Potifar se vrou, word beskryf met die Hebreeuse woord $t f \boldsymbol{t}$ ("gryp"), wat nie na 'n neutrale aksie verwys nie. Dit dui tegelyk op 'n daad met 'n seksuele konnotasie (kyk bv. Spr. 7:13 en Kottsieper, 1997:32), sowel as op 'n doelbewuste poging om iemand in jou mag te kry. Vergelyk Liwak (1995:735) se raak beskrywing in dié verband wanneer hy sê dit het te doen met 'n "zeichenhafte(r) Besitzanspruch". Ook Josef se handeling is nie 'n outomatiese refleks om haar grypende hande te ontwyk nie.

Dat Potifar se vrou wel deeglik bewus moes gewees het wat Josef se gebaar inhou, word duidelik as 'n mens noukeurig luister na haar weergawe van die gebeure aan haar huishouding. Sy manipuleer 'n belangrike element van die getuienis tot haar voordeel. In plaas daarvan om te sê dat hy sy kleed "in haar hand" (v. 13) gelos het, maak sy die bewering dat hy dit "naby haar" (v. 15) gelaat het om sodoende die blaam na Josef te verskuif en die idee te gee dat dit eintlik hy is wat vir die moeilikheid verantwoordelik is (Hamilton, 1995:467). Dat ook Josef se reaksie nie blote toeval was nie, maar gedui het op 'n baie spesifieke juridiese inhoud, word duidelik as dit vergelyk word met 'n soortgelyke daad in die Wysheidsboek van Agikar (Spreuk 77; Lindenberger, 1983:174)². Die teks lui soos volg:

As 'n slegte mens jou aan die soom van jou kleed gryp, laat dit in sy hand.

Beroep $^{3}$ jou daarna op Sjamasj.

Hy sal neem wat aan hom (= die slegte mens) behoort en dit aan jou gee.

Soos in die geval van die Josefstorie, voer albei die dramatiese persone elk 'n afsonderlike daad uit. Die slegte neem die toevlug tot 'n handeling (gryp aan die soom van die kleed) wat in die Ou Nabye Ooste wyd voorgekom het in 'n verskeidenheid religieuse en sosiale kontekste (kyk Kruger, 1988). In ooreenstemming met Ugaritteks KTU 1.6 II 9-11 en Hebreeuse tekste soos 1 Samuel 15:27 en Sagaria 8:23, kan die handeling vertolk word as 'n gebaar van smeking om iemand daartoe te bring om gehoor te gee aan 'n sekere pleidooi/versoek. In die Agikarpassasie is dit nie duidelik wat die inhoud van die versoek was nie, maar in die lig van Genesis 39:13 en Spreuke 7:13 blyk die gedagte van 'n

2 Aangedui deur Kottsieper (1997:36) en Cowley (1923:225) as Kolom xii: 13-14 en Spreuke 171172 , respektiewelik.

3 Dis die vertaling van Lindenberger (1983:174). Kottsieper (1997:36) verbind die woord met GT van $d r h$ ("om 'n relasie aan te gaan") in Siries en Mandees. Kyk ook Cowley (1923:225) wat dit weergee met: "nader tot". 
seksuele toenadering 'n sterk waarskynlikheid te wees. Dit, volgens die spreuk, moet die slagoffer ten alle koste weerstaan. Om aan te dui dat so 'n voorneme ernstig bedoel is, word die slagoffer opgeroep om die soom van die kleed, indien so 'n toenadering sou plaasvind, in die hand van so 'n persoon agter te laat. Dat die in-besit-wees van die soom van iemand se kleed daarop kan dui dat oor so 'n persoon beskik word, is bekend uit Middelbrons-Mari. Daar stel die "profeet" hom onder die koning se outoriteit deur aan hom 'n haarlok en 'n deel van die soom van sy kleed te stuur (kyk Ellermeier, 1968:102 e.v.). Vergelyk ook Dawid wat by geleentheid 'n deel van die soom van Saul se kleed afsny terwyl hy aan die slaap is (1 Sam. 24:5-6). Dit is egter nie die betekenis van die handeling in die Josef- en Agikarkontekste waarna vroeër verwys is nie. 'n Waarskynliker parallel word teëgekom in Ou Nabye Oosterse verdragstekste waar 'n verskeidenheid rituele uitgevoer word by geleentheid van die aangaan van 'n verdrag, byvoorbeeld "om die soom van die kleed vas te gryp", of "om die soom van die kleed vas te hou" (Munn-Rankin, 1956:91 e.v.; Kruger, 1988). Terwyl hierdie aksies dui op die onderwerping (gewoonlik van die vasal aan die Groot Koning), het die presiese teenoorgestelde handeling, naamlik "om die soom van die kleed te los", gedien as 'n ritueel van afvalligheid (Munn-Rankin, 1956:91; McCarthy, 1978:89).

As die Agikarpassasie teen die agtergrond hiervan weer beskou word, is dit belangrik om daarop te let dat die gebaar "om die kleed in die hand van die teenstander agter te laat" eweneens die resultaat (eindpunt) van 'n sekere proses aandui. In dié opsig stem dit ooreen met die rituele in die verdragstekste waarna bo verwys is. Net soos in die Josefverhaal, kommunikeer die agterlaat van die kleed die ruimtelike distansiëring van 'n potensieel kontaminerende bron. In die Agikarvoorbeeld word die nuanse van finaliteit nog duideliker gemerk. Eers wanneer die slagoffer se intensie duidelik blyk uit die uitvoering van die handeling, eers dan (let op die temporele "daarna"; kyk Kottsieper, 1997:36) is hy gereed of geskik om 'n nuwe relasie aan te gaan - hierdie keer met die sakrale sfeer.

\section{Die uitdrukking van emosie op 'n nie-verbale wyse}

'n Ander interessante studietema in die Hebreeuse Bybel is die nie-verbale wyse waarop verskillende menslike emosies tot uitdrukking kom. Bo is verwys na die studie van Gruber wat juis oor dié aspek handel. Hoewel sy ondersoek baie insiggewend is, is die fokus daarvan beperk omdat hy net konsentreer op die emosies van vreugde, kommer en woede. As dit vergelyk word met 'n tipologie uit die sosiale wetenskappe (vgl. byvoorbeeld Izard, 1977), wat met tien basiese emosies rekening hou (verwondering, vreugde, belangstelling, kommer, angs, woede, afkeur, minagting, skaamte en skuldgevoel), blyk duidelik dat daar nog verskeie basiese emosies in die Hebreeuse Bybel oorbly wat ondersoek kan 
word. In hierdie paragraaf word aan twee van die emosies, naamlik dié van skaamte en afkeur/minagting, aandag gegee en spesifiek aan die nie-verbale wyse waarop hulle tot uitdrukking kom.

\section{1 Skaamte 4}

Ten aanvang is dit belangrik om vas te stel wat onder die konsep emosie verstaan word. Parkinson (1994:503) verstaan daaronder die volgende: "Emotion is a relatively short-term, evaluative state focused on a particular intentional object (a person, an event, or a state of affairs) ... Emotional reactions typically include many of the following four components: appraisal of the situation, bodily response, facial expression, and changes in action readiness". Gewoonlik is die opwelling van emosie 'n natuurlike en spontane aktiwiteit. Dit sou, volgens Janney en Arndt (1992:27), "emosionele kommunikasie" genoem kon word. Daar is egter ook ' $\mathrm{n}$ ander wyse waarop emosies in interpersoonlike verhoudings tot uitdrukking kan kom. Janney en Arndt noem dit "emotiewe kommunikasie" (1992:27), wat behels dat 'n gegewe emosie doelbewus geproduseer word om sekere doelstellings te bereik. Seker een van die mees treffende voorbeelde van "emotiewe kommunikasie" in die Hebreeuse Bybel is Josef se houding teenoor sy broers. Teenoor hulle projekteer hy 'n houding van apatie en outoriteit om hulle te beweeg om sy oogmerke te bereik, naamlik om sy vader en jongste broer na Egipte te bring. Hoewel hy uiterlik egter koel en beredeneerd voorkom, is sy binneste elke keer in beroering as hy met hulle te doen het. In die opmerkings hieronder oor die emosies van skaamte en afkeur/minagting word die aandag bepaal by die gevalle waar die uitdrukking van emosie 'n spontane en intuïtiewe aktiwiteit is.

Die skaamte-emosie volg wanneer 'n sekere oogmerk nie bereik is nie. Piers en Singer (1953:11) maak in hulle bekende definisie die volgende onderskeid: Terwyl 'n skuldgevoel ontstaan wanneer die grens wat die indiwidu vir homself stel, oortree word, oorweldig die skaamtegevoel iemand wanneer die mikpunt wat gestel word, nie bereik is nie.

Indien die skaamtegevoel dan volg op die negatiewe waardering van 'n gegewe situasie ooreenkomstig die definisie hierbo, sal die effek daarvan op een of ander wyse in 'n liggaamlike reaksie tot uitdrukking kom. Darwin (1872:322), wat algemeen gereken word as die grondlegger van die studie van liggaamstaal in die moderne tyd, merk op: "Under a keen sense of shame there is a strong desire for concealment. We turn away the whole body, more especially the shame, which we endeavour to hide in some manner". Tomkins (1963:133) stem hiermee saam wanneer hy benadruk: "Shame turns the attention of the self and others away 
from other objects to this most visible residence of self ... awareness of the face by itself is an integral part of the experience of shame".

As die voorkoms van nie-verbale manifestasies van die skaamte-emosie in die Hebreeuse Bybel nagegaan word, lewer dit die volgende gegewens op:

\section{- Evaluering van die situasie}

In die gevalle in die Hebreeuse Bybel waar dié emosie teëgekom word, word die betrokke situasies wat daartoe aanleiding gegee het, altyd negatief geëvalueer (2 Sam. 19:6; Jer. 2:37, 7:19, 14:3-4, 31:19, 48:39, 51:51; Eseg. 7:18; Dan. 9: 7-8; Esra 9:7; 2 Kron. 32:31). Die mikpunt of standaard wat gestel is, is nie bereik nie.

\section{- Gesigsuitdrukking}

In ooreenstemming met die algemene psigologie van skaamte, is die gesig die lokus waar dié emosie vertoon word (bv. 2 Sam. 19:6; Jer. 51:51; Eseg. 7:18). By ses geleenthede (Jer. 7:19; Ps. 44:16; Dan. 9:7-8; Esra 9:7; 2 Kron. 32:31) word daar pertinent verwys na die "skaamte van die gesig", wat nie "openbare skande" ("öffentliche Schande") is soos beweer word nie (Klopfenstein, 1972:35), maar die gevoel van 'n verhoogde bewustheid van die self en die gesig (Tomkins, 1963:133, 143).

\section{- Liggaamlike respons}

Soos aangedui, manifesteer die gevoel van skaamte gewoonlik in een of ander liggaamlike aktiwiteit wat primêr daarop gerig is om te ontkom (deur bedekking of ontvlugting) aan die omstandigheid wat die skaamte veroorsaak het. Die Hebreeuse Bybel verwys na die volgende spontane aksies wat almal daarop gemik is om die sigbaarheid van die gesig in dié opsig te verminder: "om die rug te draai" (Jer. 48:39; kyk ook Jer. 14:3); "om die gesig neergeslaan te hou" (Esra 9:6) en "om die hande oor die kop te hou" (Jer. 2:37). Laasgenoemde gebaar word meestal verkeerdelik as een van rou vertolk.

\subsection{Afkeur/minagting}

Die emosies van afkeur en minagting is ingebore defensiewe response wat baie in gemeen het (Ekman, 1982:377). Minagting bewerk 'n "cool and distant" gevoel, terwyl die emosie van afkeur die begeerte laat ontstaan om ontslae te raak, of jouself te verwyder van die objek of omstandigheid wat aanleiding tot so 'n gevoel gee (Izard, 1977:336). Minagting gaan gewoonlik gepaard met een of ander vorm van devaluasie van die persoon teenoor wie dié emosie gevoel word (Izard, 1977:337). In albei die emosies is daar meestal ook 'n element van leedvermaak aanwesig (Izard, 1977:89). 
Vanselfsprekend kan hierdie emosies op veelvuldige wyses (op 'n verbale en selfs op 'n fisiese manier) tot uitdrukking kom. Tog word die nie-verbale manifestasies daarvan dikwels baie meer pynlik ervaar deur die slagoffers teen wie dit gerig is. Dit is dan ook nie vreemd nie dat die meeste voorbeelde hiervan in die Psalmboek is waar beskryf word hoe die bidder byna permanent uitgelewer is aan die geestelike teisteringe van die teenstanders (Kruger, 1993). Die aksies waarna hieronder verwys word, kan gereken word as voorbeelde van nie-verbale manifestasies van sodanige emosies, omdat die begeerte om jouself los te skud van die objek van afsku, en die begeerte tot ontmensliking en leedvermaak grondliggend aan dié aksies is. 'n Lys van voorbeelde gaan gegee word sonder om 'n volledige kontekstuele analise van elk aan te bied:

- “die skud van die kop" (2 Kon. 19:21; Jer. 18:165; Ps. 22:8, 44:15; Klaagl. 2:15)

- "die hande oor iemand klap" (Eseg. 25:6; Nah. 3:19; Job 27:23; Klaagl. 2:15)

- “fluit en sis" (Sef. 2:15; Job 27:23; Klaagl. 2:15, 16 ens.)

- "die mond teen iemand oopmaak" (Klaagl. 2:16)

- "om die tande teen iemand te kners" (Ps. 35:16, 37:12; Job 16:9; Klaagl. 2:16)

- "om die hand te skud" (Sef. 2:15)

- "om die mond teen iemand oop te spalk" (Job 16:10)

- “om 'n opening met die lip te maak" (Ps. 22:8)

- "om met die voet te stamp" (Eseg. 6:11, 25:6)

\section{Nie-verbale kommunikasie en narratiewe literatuur}

'n Aspek wat tot nou toe deur ondersoekers baie verwaarloos is, is hoe nieverbale kommunikasie tot uitdrukking kom in Bybels-Hebreeuse narratiewe literatuur. Verhale soos byvoorbeeld die Josef- en Rutstories is al indringend vanuit verskillende hoeke bekyk: die sintaktiese, semantiese, retoriese, strukturele aspekte, en so meer. Die ewe belangrike bron van nie-verbale inligting word gewoonlik verontagsaam, of wanneer wel daarna verwys word, nie genoegsaam verreken nie. In die studie van die Klassieke literatuur is veel meer aandag aan dié aspek gewy - iets wat interessante resultate opgelewer het (kyk bv. Poyatos, 1977, Holoka, 1987, Lateiner, 1987). Behalwe 'n aantal algemene studies met 'n beperkte skopus [kyk byvoorbeeld die studies van Matthews (1995) en Prouser (1996 en 1998) oor die simboliek van klere in die Josef- en Dawidstories,

$5 \quad$ Vir 'n bespreking van die beth gesticulationis hier, soos Jenni dit noem, sowel as in Esegiël 6:11, 25:6, Psalm 22:8 en Job 16:9, vgl. Jenni (1997:150 e.v.). 
respektiewelik], is niks vergelykbaar oor die Hebreeuse Bybel nog onderneem nie. As in gedagte gehou word, soos Poyatos tereg sê (1977:296 e.v.), dat

- 'n substansiële deel van enige narratiewe teks daarop gerig is om nie-verbale inligting oor te dra, en

- dat die skrywer, deur dit te doen, erkenning gee aan die beperkinge van die geskrewe tipografiese wyse van inligtingoordrag,

dan spreek dit vanself dat die analise van enige narratiewe teks, ook in die Hebreeuse Bybel, vanuit hierdie perspektief baie insiggewend kan wees. Aspekte van sodanige nie-verbale informasie kan, onder andere, die volgende wees: fisieke en persoonlike voorkoms, ander seine wat deur die liggaam as "a socializing organism" (Poyatos, 1977:297) geproduseer word, byvoorbeeld gebare, liggaamshoudings, liggaamlike bewegings, gesigsuitdrukkings en liggaamskontak (bv. territorialiteit, of spacial behaviour/ proxemics, soos dit ook deur Hall genoem word; kyk ook Holoka, 1987, wat dié aspekte in die Klassieke ondersoek).

As die Rut-novelle as voorbeeld geneem word, dan is die meeste van die aspekte waarna nou verwys is, ook daarin aanwesig. So 'n uitvoerige ondersoek wat al die aspekte dek, regverdig egter ' $n$ afsonderlike studie. In die volgende paragraaf gaan net 'n paar opmerkings gemaak word oor die nie-verbale kategorie "proksemika" (proxemics/ spatial behaviour), en meer spesifiek oor die weergawe daarvan in Hoofstuk 2-3 waar die interaksie tussen die twee hoofkarakters (Rut en Boas) beskryf word. In dié hoofstukke verraai proksemika nogal heelwat oor die innerlike emosies van die betrokkenes.

Die skepper van die begrip proksemika defineer dit as "interrelated observations and theories of man's use of space as a specialized elaboration of culture" (Hall, 1966:1). Hy gaan dan voort om vier "sones van betrokkenheid" ("zones of involvement") te onderskei: 'n intieme, 'n persoonlike, 'n sosiale en openbare sone. Die beginsel waarvolgens proksemika werk is: hoe nader die ruimtelike afstand van die deelnemers aan mekaar, hoe meer betrokke by mekaar; hoe verder, hoe minder betrokke.

By "intieme afstand" is die "naby fase", byvoorbeeld dié van "love-making and wrestling, comforting and protecting" (Hall, 1966:110). In die "naby fase" van "persoonlike afstand" ("personal distance") kan die betrokkenes nog aan mekaar raak (1966:113). In "sosiale afstand" ("social distance") is die wyses van sosiale interaksie meestal dié van hoor en sien (1966:114). Ten slotte onderskei hy ook 'n "openbare afstand" ("public distance") waar die erkenning van die ander op sosiale gebied nie meer ' $n$ voorvereiste is nie (1966:116). 
As hierdie verskillende "sones van betrokkenheid" op die verloop van die gebeure in Rut 2-3 van toepassing gemaak word, dan word bemerk dat daar 'n interessante wisselwerking is tussen die verskillende sosiale afstande. Aan die begin handhaaf die karakters 'n openbare afstand, maar soos hulle met mekaar bekend raak, is daar 'n subtiele beweging deur die sosiale en persoonlike afstande wat uiteindelik kulmineer in die inname van die intieme ruimte. Hierdie oorgange word gekommunikeer deur middel van nie-verbale handelinge wat bedrewe gekombineer is met "beleefde taal" ("politeness in speech"; vir laasgenoemde aspek kyk Watts et al., 1992).

Toe Boas en Rut mekaar vir die eerste keer (2:3) ontmoet, is dit op die vlak van openbare afstand. Rut is een van diesulkes (volgens die bepalings in Lev. 19:9-10 was dit vreemdes en armes) wat toegelaat is om are op te tel agter die graansnyers. Vir Boas is sy op daardie stadium deel van die openbare domein. Daarom weerhou hy hom daarvan om haar direk aan te spreek en doen hy navraag oor haar identiteit deur middel van sy voorman (v. 5). Wanneer hy hom vir die eerste keer direk tot haar wend (v. 8), word sy gepromoveer tot sy sosiale sfeer. Dit word duidelik uit die wyse waarop hy haar aanspreek, sowel as uit die voorregte wat hy aan haar toesê. Sy word aangespreek as "my dogter" (v. 8), wat volgens Ehlich (1992:82) daarop dui dat hy (Boas) haar verwelkom as lid van sy familiegroep (misjpaga). Synde nou deel van Boas se sosiale sfeer, word sy ook toegelaat om deel te hê aan die voorregte wat hy bied: om van sy waterbronne te gebruik en om onder sy beskerming te val (v. 9).

In 'n volgende beweging word sy ingetrek in sy persoonlike sfeer. Dit gebeur wanneer sy uitgenooi word om deel te hê aan hulle gesamentlike maaltyd (v. 14). Om uitgenooi te wees na iemand se maaltyd was volgens Semitiese gebruik nie 'n ligtelike saak nie. Dit het beteken dat die gasheer jou op dieselfde vlak stel as sy eie familie (Smith, 1923:265). Wat in dié geval met Rut gebeur, word baie treffend saamgevat deur Sasson (1979:55):

It is to be noted that this act of sitting on the same side as the reapers must certainly have implied acceptance in the 'familia'. Beyond receiving water promised her in verse 9, she is now to share in the communal meal. Furthermore, Boaz himself introduces her in the circle of his family by presenting her with the first handfuls of roasted grain .... It is not impossible that this act of Boaz was ceremonial, perhaps quasi-legal in nature.

Oor die binnedringing van die intieme sfeer word berig in die bekende episode in Hoofstuk 3, wat handel oor die gebeure op die dorsvloer. Die woordeskat van die eerste verse (v. 1-8) bevat verskillende dubbelsinnige terme waaroor hier nie verder uitgebrei sal word nie (kyk die resente kommentaar van Bush, 1996). Dit is belangrik om daarop te let dat Rut hier, in teenstelling met die voorafgaande 
gebeure, die inisiatief neem. Haar binnedringing van Boas se intieme sfeer vind in twee fases plaas. In 'n eerste beweging kom sy binne "the distance of lovemaking", om Hall se beskrywing (1966:110) te gebruik. Dit gebeur wanneer sy stilletjies gedurende die nag nadersluip, "die area van sy bene oopmaak en by sy voete inkruip" (3:6). Hoe die aktiwiteit ook al verstaan word, of die presiese posisie waar sy plaasgeneem het ("by sy voete/langs hom"; vir lg. moontlikheid, kyk Bush, 1996:158 en Zenger, 1986:67), is nie eintlik van belang nie. Dit was egter fisies so naby aan hom dat dit hom in sy slaap gesteur het (Sasson, 1979:93). Die oomblik dat sy egter dié posisie bereik, neem sy ook 'n nuwe roldefinisie aan. In plaas van die onderdanige rol wat sy tot nou toe gespeel het, manifesteer sy haar in hierdie nuwe posisie as Boas se gelyke (Berquist, 1993:30). Dit word duidelik as ag geslaan word op die manier waarop sy haar in hierdie omstandighede aanbied. By haar en Boas se eerste ontmoeting gaan sy nog deur as 'n vreemde (2:6). 'n Rukkie later word sy opgegradeer tot 'n slavin (2:13). Hier in 3:9 beskryf sy haarself as 'n diensmeisie wat statusgewys hoër op die sosiale leer is as die slavin en wat verwys na 'n hubare jongvrou (Sasson, 1979: 80-81). Vanuit hierdie nuwe status daag sy Boas uit om die finale "proksemiese" stap te neem: "Sprei die soom van u kleed uit oor u diensmeisie" (3:9). Die gebaar verwys na 'n huweliksvoorstel (Kruger, 1984). Met die aanvaarding van dié uitnodiging (wat later volgens Hoofstuk 4 'n werklikheid word) brei hy as't ware sy persoonlike sfeer uit om ook hare te omvat. Daarmee verklaar hy hom bereid om haar beskerming en versorging op hom te neem - die beskerming en versorging wat hy as man volgens Semitiese huweliksreg aan haar verskuldig was. Daarmee aanvaar hy die verantwoordelikheid wat Rut tot op daardie stadium vir haarself en Naomi gehad het.

\section{Slotopmerking}

In hierdie bydrae is alleen verwys na sekere aspekte in die veel omvattender veld van nie-verbale kommunikasie in die Hebreeuse Bybel. Verskeie interessante aspekte wag nog om ontgin te word. Hier word net twee genoem. Die eerste gaan oor religieuse simboliek soos dit veral in die kultiese tekste in die Pentateug beskryf word. ' $n$ Ander interessante tema vir ondersoek is die samehang tussen nie-verbale kommunikasie en sosiale waardes. 'n Bundel opstelle onder redaksie van Bremmer en Roodenburg (1991) vanuit laasgenoemde perspektief op die Klassieke, Middeleeuse en moderne wêrelde het getoon watter interessante en insiggewende afleidings op grond van nie-verbale inligting gemaak kan word.

\section{Bibliografie}

BERQUIST, J.L. 1993. Role dedifferentiation in the Book of Ruth. Journal for the Study of the Old Testament, 57:23-37.

BREMMER, J. \& ROODENBURG, H. 1991. A cultural history of gesture: from antiquity to the present day. Cambridge : Polity Press.

BUSH, F.W. 1996. Ruth, Esther. (Word Biblical Commentary 9.) Dallas : Word Books. 
COWLEY, A. 1923. Aramaic papyri of the fifth century B.C. Oxford : Clarendon Press.

DARWIN, C. (edited by F. Darwin) 1872. The expression of the emotions in man and animals. London : John Murray.

EHLICH, K. 1992. On the historicity of politeness. (In Watts, R.J., Ide, S. \& Ehlich, K. eds. Politeness in language. Mouton : De Gruyter. p. 71-107.)

EKMAN, P. \& FRIESEN, W.V. 1969. The repertoire of nonverbal behavior: categories, origins, usage, and coding. Semiotica, 1:49-98.

EKMAN, P. 1982. Emotion in the human face. New York : Pergamon Press.

ELLERMEIER, F. 1968. Prophetie in Mari und Israel. Herzberg : Verlag Erwin Jungfer.

FARNELL, B. 1996. Gesture and movement. (In Levinson, D. \& Ember, M. eds. Encyclopedia of cultural anthropology, vol. II. New York : Henry Holt. p. 536-541.)

GOLDZIHER, I. 1886. Ueber Geberden- und Zeichensprache bei den Arabern. Zeitschrift für Völkerpsychologie und Sprachwissenschaft, 7:369-386.

GRUBER, M.I. 1980. Aspects of nonverbal communication in the ancient Near East. Rome : Biblical Institute Press.

HALL, E.T. 1973 (1953). Silent language. Second edition. Garden City : Anchor Press.

HALL, E.T. 1966. The hidden dimension. New York : Doubleday.

HAMILTON, V.P 1995. The book of Genesis 18-50. (NICOT.) Grand Rapids : Eerdmans.

HIBBITS, B.J. 1992. "Coming to our senses": communication and legal expression in performance cultures. Emory Law Journal, 41:873-960.

HILLERS, D.J. 1990. Rite: ceremonies of law and treaty in the Ancient Near East. (In Firmage, E. B. ed. Religion and law. Biblical-Judaic and Islamitic perspectives. Winona Lake : Eisenbrauns. p. 351-364.)

HOLOKA, J.P. 1987. Nonverbal communication in the classics: research opportunities. (In Poyatos, F. ed. Advances in nonverbal communication: sociocultural, clinical, esthetic and literary perspectives. Amsterdam : Benjamins. p. 237-254.)

IZARD, C.E. 1977. Human emotions. London : Plenum Press.

JANNEY, R.W. \& ARNDT, H. 1992. Intracultural tact versus intercultural tact. (In Watts, R. J., Ide, I. \& Ehlich, K. eds. Politeness in language. Mouton : De Gruyter. p. 21-41.)

JENNI, E. 1997. Verba gesticulationis im Hebräischen. (In Jenni, E. ed. Studien zur Sprachwelt des Alten Testaments. Stuttgart : Kohlhammer. p. 150-161.)

KENDON, A.1981. Introduction: current issues in the study of "nonverbal communication". (In Kendon, A. ed. Nonverbal communication, interaction and gesture. The Hague : Mouton. p. 1-53.)

KIENAST, B. 1996. Mündlichkeit und Schriftlichkeit im heilschriftlichen Rechtswesen. Zeitschrift für altorientalische und Biblische Rechtsgeschichte, 2:115-130.

KILMER, A.D. 1974. Symbolic gestures in Akkadian contracts from Alalakh and Ugarit. Journal of the American Oriental Society, 94:177-83.

KLOPFENSTEIN, M.A. 1972. Scham und Schande nach dem Alten Testament. Zürich : Theologischer Verlag.

KOTTSIEPER, I. 1997. El - ferner oder naher Gott? Zur Bedeutung einer semitischen Gottheit in verschiedenen sozialen Kontexten im 1. Jtsd. v. Chr. (In Albertz, R. \& Otto, S. eds. Religion und Gesellschaft. (AOAT.) Münster : Ugarit-Verlag. p. 25-74.)

KRUGER, P.A. 1984. The hem of the garment in marriage. The meaning of the symbolic gesture in Ruth 3:9 and Ezek. 16:8. Journal of Northwest Semitic Languages, XII:7986.

KRUGER, P.A. 1988. The symbolic significance of the hem in 1 Sam. 15:27. (In Claassen W. ed. Text and context. Old Testament and Semitic Studies for F.C. Fensham. Sheffield : Sheffield University Press. p. 105-116.) 
KRUGER, P.A. 1990. Symbolic acts relating to Old Testament treaties and relationships. Journal for Semitics, 2(2):156-170.

KRUGER, P.A. 1993. Simboliese handelinge in die Psalms. Nederduitse Gereformeerde Teologiese Tydskrif, 34(2):115-123, Jun.

KRUGER, P.A. 1996. The psychology of shame and Jeremiah 2:36-37. Journal of Northwest Semitic Languages, 22(2):79-88.

LATEINER, D. 1987. Nonverbal communication in the Histories of Herodotus. Arethusa, 20:83-119.

LINDENBERGER, J.M. 1983. The Aramaic Proverbs of Ahiqar. Baltimore : Johns Hopkins University Press.

LIWAK, R. 1995. tf $\boldsymbol{\uparrow}$. (In Botterweck, G.J. \& Ringgren, H. reds. Theologisches Wörterbuch zum Alten Testament, vol. VIII. Stuttgart : Kohlhammer. p. 732-741.)

MACKIE, G.M. 1899. Gestures. (In Hastings, J. ed. A dictionary of the Bible, vol. II. Edinburgh : Clark. p. 162-163.)

MAINE, H.S. 1986 (1861). Ancient law. Tucson : University of Arizona Press.

MALUL, M. 1988. Studies in Mesopotamian legal symbolism. (AOAT 221.) NeukirchenVluyn: Neukirchener Verlag.

MATTHEWS, V.H. 1995. The anthropology of clothing in the Joseph narrative. Journal for the Study of the Old Testament, 65:25-36.

McCARTHY, D.J. 1978. Treaty and covenant. Rome : Biblical Institute Press.

MUNN-RANKIN, J. 1956. Diplomacy in Western Asia in the early second millennium BC. Iraq, 18:68-110.

PARKINSON, B. 1994. Emotion. (In Colman, A.M. ed. Companion Encyclopedia of Psychology. London : Routledge. p. 483-503.)

PETCHOW, H. 1971. Gewand(saum) im Recht. (In Weidner, E. \& Von Soden, W. eds. Reallexikon der Assyriologie, III. Berlin : De Gruyter. p. 318-322.)

PIERS, G. \& SINGER, M.S. 1953. Shame and guilt: a psychoanalytic and cultural study. Springfield : Charles Thomas.

POLHEMUS, T. 1975. Social bodies. (In Benthall, J. \& Polhemus, T. eds. The body as medium of expression. London : Penguin Books. p. 13-35.)

POYATOS, F. 1977. Forms and functions of nonverbal communication in the novel: a new perspective of the author-character-reader relationship. Semiotica, 21:295-336.

POYATOS, F. 1987. Cross-cultural perspectives in nonverbal communication. C.J. Hogrefe : Toronto.

PROUSER, O.H. 1996. Suited to the throne: the symbolic use of clothing in the David and Saul narratives. Journal for the Study of the Old Testament, 71:27-37.

PROUSER, O.H. 1998. Clothes maketh the man. Bible Review, 24:24-27.

RUESCH, J. \& KEES, W. 1956. Nonverbal communication: notes on the visual perception of human relationships. Berkeley : University of California Press.

RUMMEL, S. 1976. Clothes maketh the man - an insight from ancient Ugarit. Biblical Archaeology Review, 2(2):6-8.

SASSON, J.M. 1979. Ruth: a new translation with a philological and a formalist-folklorist interpretation. Baltimore : The Johns Hopkins University Press.

SCHMITT, J-C. 1991. The rationale of gestures in the West. (In Bremmer, J. \& Roodenburg, H. eds. A cultural history of gesture: from antiquity to the present day. Cambridge : Polity Press. p. 59-70.)

SCHMIDT-WIEGAND, R. 1971. Gebärden. (In Erler, A. et al. eds. Handwörterbuch zur deutschen Rechtsgeschichte. Berlin : Erich Schmidt Verlag. p. 1411-1419.)

SCHMIDT-WIEGAND, R. 1982. Gebärdensprache im mittelalterlichen Recht. Frühmittelalterliche Studien, 16:363-379. 
SITTL, C. 1890. Die Gebärden der Griechen und Römer. Leipzig : Teubner Verlag.

SMITH, W.R. 1923 (1894). The religion of the Semites. Tweede Uitgawe. New York : Meridian.

TOMKINS, S. 1963. Affects, imagery, conciousness, vol. 2. New York : Springer.

VAN GENNEP, A. 1965 (1909). The rites of passage. Second edition. London : Routledge.

VIBERG, A. 1992. Symbols of law. (Coniectanea Biblica OT Series 34.) Stockholm : Almqvist \& Wiksell.

WATTS, R.J., IDE, S. \& EHLICH, K. eds. 1992. Politeness in language. Mouton : De Gruyter.

ZENGER, E. 1986. Das Buch Ruth. (Zürcher Bibelkommentare 8.) Theologischer Verlag : Zürich. 